\title{
Correlation among Root Canal Configuration, Quality of Filling, and Its Sealability
}

\author{
Ricardo Machado ${ }^{1, \odot ~ R i c a r d o ~ K o e t z ~}{ }^{2, \odot ~}$ Daniel Comparin ${ }^{2, \odot}$ Luiz Rômulo Alberton ${ }^{3, \odot}$ \\ Lucas da Fonseca Roberti Garcia, ${ }^{4, \odot}$ Ulisses Xavier da Silva Neto ${ }^{1, \odot}$
}

${ }^{1}$ Department of Endodontics, School of Health and Bioscience, Pontifical Catholic University of Paraná, Curitiba, Paraná, Brazil

${ }^{2}$ Department of Endodontics, School of Dentistry, Paranaense University, Francisco Beltrão, Paraná, Brazil

${ }^{3}$ Department of Veterinary Medicine and Graduate Program in Animal Science, Paranaense University, Umuarama, Paraná, Brazil

${ }^{4}$ Department of Dentistry, Endodontics Division, Health Sciences Center, Federal University of Santa Catarina - UFSC, Florianópolis, Santa Catarina, Brazil

Eur ] Dent 2021;15:568-573
Address for correspondence Ricardo Machado, DDS, MSc, PhD, Rua Brasília, n. 300, Apto. 503, Centro, Navegantes, Santa Catarina 88.370-100, Brazil

(e-mail: ricardo.machado.endo@gmail.com).

\begin{abstract}
Keywords

- filling

- root canal configuration

- sealability
\end{abstract}

Objective This study aimed to evaluate the existence of possible correlations among root canal configuration, quality of filling, and its sealability.

Materials and Methods Sixty human mandibular central incisors were selected for this study. The teeth were prepared with the Profile 04 system up to instrument 35/0.04 and irrigated with $2.5 \mathrm{~mL}$ of $2.5 \%$ sodium hypochlorite at each instrument change. Root canal filling was performed by the lateral compaction technique, using gutta-percha and an epoxy resin-based sealer (AH Plus) labeled with $0.1 \%$ Rhodamine $B$ dye. Afterward, the specimens were submitted to fluid filtration tests to assess the sealability of the filling. Cross-sections were obtained at $-3,-6$, and $-8 \mathrm{~mm}$ from the root apex and submitted to a metallographic treatment to determine the root canal configuration and the percentage of gutta-percha filled areas. The data were statistically analyzed by the Grubbs test. Pairs of correlations were analyzed by applying the Spearman test at a level of significance of $5 \%$.

Results No correlation was observed among the analyzed variables as follows: root canal configuration versus filling quality (Spearman's rho $=0.031$ ); filling quality versus sealability (Spearman's rho $=0.219$ ); and root canal configuration versus sealability (Spearman's rho $=0.184$ ).

Conclusion The root canal configuration did not affect the quality of the filling and its sealability.
DOI https://doi.org/

$10.1055 / \mathrm{s}-0041-1724158$ ISSN 1305-7456. (c) 2021. European Journal of Dentistry.

This is an open access article published by Thieme under the terms of the Creative Commons Attribution-NonDerivative-NonCommercial-License, permitting copying and reproduction so long as the original work is given appropriate credit. Contents may not be used for commercial purposes, or adapted, remixed, transformed or built upon. (https://creativecommons.org/licenses/by-nc-nd/4.0/).

Thieme Medical and Scientific Publishers Pvt. Ltd. A-12, 2nd Floor, Sector 2, Noida-201301 UP, India 


\section{Introduction}

The main purpose of the endodontic treatment is to maintain or re-establish the health of periapical tissues by cleaning, shaping, and filling the root canal system. ${ }^{1,2}$ Cleaning is achieved by the associated use of endodontic instruments and chemical substances (irrigating solutions and intracanal dressings). ${ }^{1}$ After, the root canal must be properly filled with inert materials (sealer and gutta-percha) in order to maintain the cleaning achieved at the previous stages. ${ }^{1,2}$ The root canal filling aims to trap the remaining microorganisms within the dentinal tubules to interrupt the supply of nutrients necessary for their survival and avoid contamination or recontamination. ${ }^{2}$

Schilder ${ }^{3}$ and Epley et $\mathrm{al}^{4}$ have reported that the root canal filling must contain a greater amount of gutta-percha than sealer, filling the irregularities of the previously prepared root canal in its entire length. Therefore, the percentage of gutta-percha filled areas (PGFA) has been used to evaluate the quality of root canal filling. ${ }^{5}$

The quality of the endodontic filling may be also assessed by its sealability. For this reason, several leakage testing methods have been used, such as the dye penetration, ${ }^{6}$ clearing teeth clearing, ${ }^{6}$ radioactive isotope testing, ${ }^{7}$ bacterial penetration, ${ }^{8}$ glucose leakage, ${ }^{9}$ electrochemical testing, ${ }^{10}$ and fluid filtration. ${ }^{11}$ The latter test has been claimed as the most reliable method for determining coronal and apical leakage in endodontics. ${ }^{11-14}$

The majority of studies which assessed the quality of root canal filling have been conducted so far in teeth with flattened canals. Van der Sluis et al ${ }^{13}$ demonstrated that mandibular incisors had root canal filling with a larger number of voids, lower PGFA and higher leakage values than canines. Machado et $\mathrm{al}^{12}$ assessed the leakage rates and the presence of voids in filled mandibular incisors. In both studies, ${ }^{12,13}$ the leakage rates were not affected by the quality of filling. However, the root canal configuration was not considered as a primary factor for performing the analyses.

To the best of our knowledge, no research has been conducted so far assessing the impact of root canal configuration on the quality and sealability of filling. The purpose of the present study was to investigate the existence of a possible correlation among these three variables by means of analysis in pairs of the following factors: root canal circularity, PGFA, and fluid filtration rates. The null hypothesis tested was that there would be no significant correlations among the three variables.

\section{Materials and Methods}

\section{Specimen Selection}

After approval of the Ethics Committee of the Pontifical Catholic University of Paraná, Curitiba, Paraná, Brazil (n. 5314), 60 freshly extracted human mandibular central incisors were selected. The selected teeth must have a single and straight canal, fully formed root with free foraminal access, and no signs of resorption or previous endodontic treatment. These features were confirmed by clinical analysis under magnification $(\times 4)$ and radiographic examination in both buccolingual and mesiodistal directions.

\section{Specimen Preparation}

The crowns of the teeth were removed by using a low-speed steel cutting disc (Isomet-Buehler; Lake Bluff, United States), under copious water cooling, standardizing the length of the roots at $13 \mathrm{~mm}$. Pre-flaring of the cervical and middle thirds of each root canal was performed with sizes 4, 3, and 2 Gates Glidden drills (Dentsply-Maillefer; Ballaigues, Switzerland) by introducing each instrument $2 \mathrm{~mm}$ deeper into the canal than the previous one. The working length $(\mathrm{WL})$ was determined by inserting a size $15 \mathrm{~K}$-Flexofile instrument (Dentsply-Maillefer) until it could be visualized at the apical foramen and subtracting $1 \mathrm{~mm}$ from this measurement. Apical foramina were standardized by preparing the root canals in their real length up to a size $25 \mathrm{~K}$-Flexofile instrument (Dentsply-Maillefer). The mechanical preparation was performed with the Profile 04 System (Dentsply-Maillefer) up to size 35. The root canals were irrigated at each instrument change with $2.5 \mathrm{~mL}$ of freshly prepared $2.5 \% \mathrm{NaOCl}$ solution (Fórmula \& Ação, São Paulo, Brazil), followed by a final flush with $3 \mathrm{~mL}$ of $17 \%$ ethylenediaminetetraacetic acid (Fórmula \& Ação) for 3 minutes at the end of chemomechanical preparation. In total, $5 \mathrm{~mL}$ of sterile water (Fórmula \& Ação) were used as a final rinse.

\section{Root Canal Filling}

The previously prepared root canals were filled by the lateral compaction technique. After drying with absorbent paper points (Dentsply-Maillefer), the active portion of a size $20 \mathrm{~K}$-Flexofile instrument was recovered with the sealer (AH Plus, Dentsply-DeTrey, Konstanz, Germany) to insert approximately $10 \mu \mathrm{L}$ into the canal under counterclockwise rotation. Previously, the sealer was labeled with $0.1 \%$ rhodamine B dye (Sigma-Aldrich, St. Louis, Missouri, United States) for further analysis by optical light microscopy.

A prefitted size 35/0.04 gutta-percha cone (DentsplyMaillefer) was used as the master cone. B8 accessory cones (Tanari, Manacapuru, Brazil) were used for lateral compaction. The filled roots were stored at $37^{\circ} \mathrm{C}$ and $100 \%$ humidity for 7 days to allow the sealer setting. Specimens preparation and root canal fillings were performed by a single researcher and experienced endodontist (R.M.).

\section{Analysis of Filling Sealability by Fluid Filtration Test}

The fluid filtration test was used to determine the apical leakage. The root apex was connected to a Luer-type metal needle by means of a plastic tube. The margin allowed for leakage in the tested groups was quantified according to the movement of a small air bubble inside a $25 \mu \mathrm{L}$ micropipette (Microcaps-Fisher Scientific, Philadelphia, United States). The interior of the pipette and the entire system was filled with distilled water and a pressure of 10 psi was applied. After making sure there was no leakage in the connections, the system was activated and balanced for 4 minutes. The volume of fluid was calculated by observing the air bubble displacements, expressed in $\mu \mathrm{L} / \mathrm{min}^{-1} \times 10 \mathrm{psi}$. The 
measurements were performed at 2-minute intervals in a time interval of 8 minutes.

\section{Analysis of the Root Canal Configuration by Calculating the Circularity Factors and Quality of the Fillings by PGFA Determination}

Each specimen was horizontally sectioned at 3, 6, and $8 \mathrm{~mm}$ from the apex by using a low-speed steel cutting disc (Isomet-Buehler). Three dentin slices per root were obtained, resulting in a total of 180 dentin slices. A standard polishing procedure with a wet sandpaper in the following order of granulation (200,300,400, and 600) was performed under copious water cooling. Next, the coronal surface of

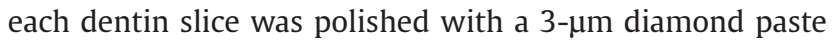
to produce a high-reflection surface. Each dentin slice was observed under a high-resolution stereomicroscope to acquire images at 1,048 $\times 1,048$ pixels, covering the entire root canal ( $\mathbf{- F i g}$. 1A). For each image, the perimeter, largest diameter and PGFA were determined by using the AxioVision Software 4.11 (Carl Zeiss, Jena, Germany; - Fig. 1B-D).

In order to determine the circularity factors, the following formula was used: $4 \times$ canal area $/ \pi(3.14) \times$ (largest diameter $)^{2}{ }^{15}$ The area occupied by gutta-percha was converted into percentage considering the total area of the root canal.

For each specimen, three values were determined (one per third), for both the PGFA and for the circularity factors. By a simple arithmetic mean, a final single value was established for each variable.

\section{Statistical Analysis}

Initially, the normality of the data was tested by the Anderson-Darling test. The outlier values were identified by means of the Grubbs test, and pairs of correlations were analyzed by the Spearman test. All the analyses were performed by using the software Minitab v. 17.0 (Minitab Inc.; State College, Pennsylvania, United States) at a level of significance of $5 \%$.

\section{Results}

The analysis of the pairs of the assessed variables had no significant correlation. Therefore, the null hypothesis tested was accepted (-Table 1 and - Figs. 2-4).
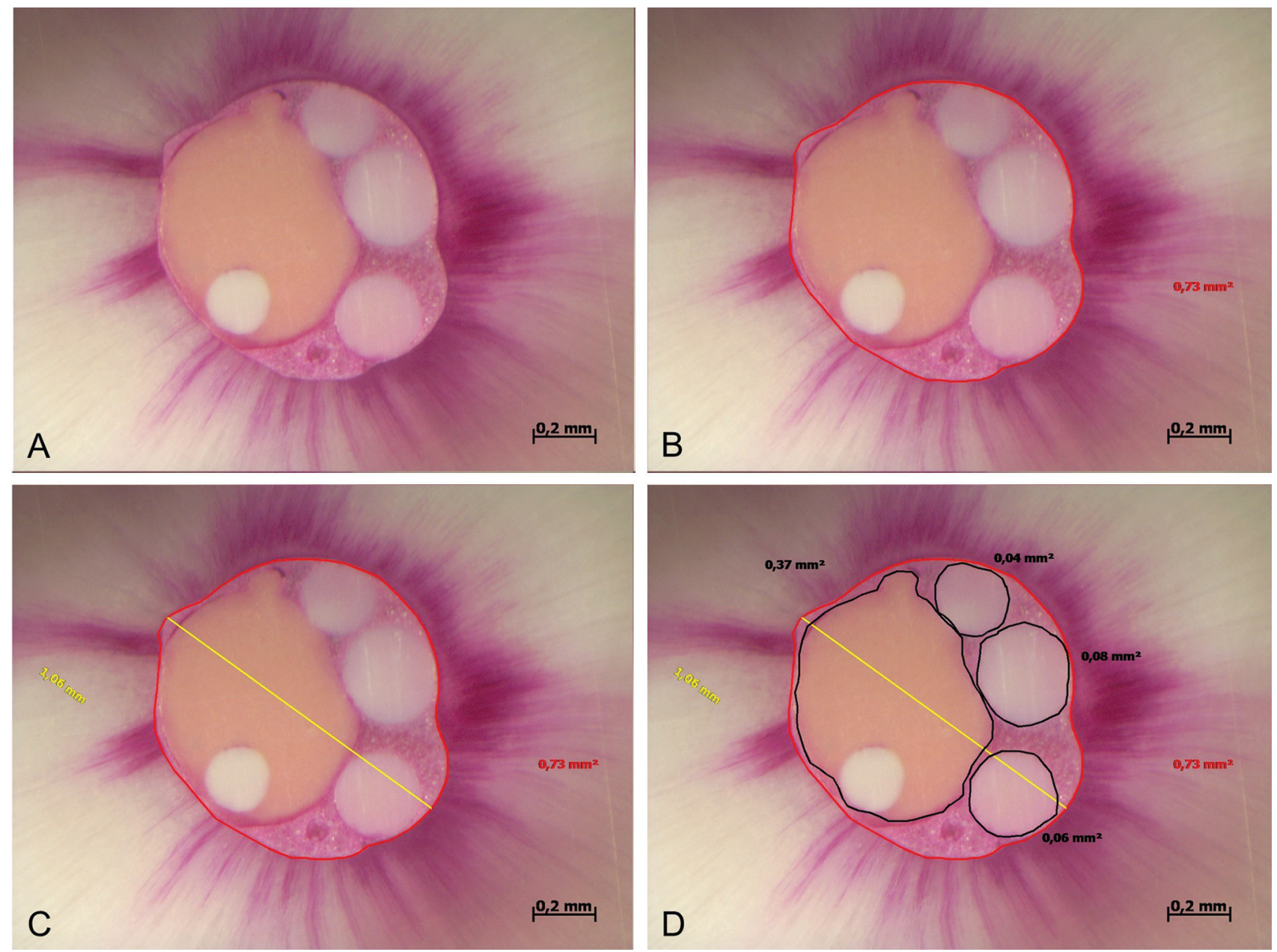

Fig. 1 Illustrative optical images relative to the measurements performed: (A) root canal; (B) total cross-sectional area of the root canal; (C) longest distance between the root canal walls; and (D) areas occupied by gutta-percha. 
Table 1 Variables (data), quantitative, and qualitative analyses of the assessed correlations

\begin{tabular}{|l|l|l|}
\hline $\begin{array}{l}\text { Variables } \\
\text { compared } \\
\text { (data) }\end{array}$ & $\begin{array}{l}\text { Correlation } \\
\text { analysis values } \\
\text { (Spearman's rho) }\end{array}$ & Correlation \\
\hline $\begin{array}{l}\text { Root canal } \\
\text { configuration } \times \\
\text { filling quality } \\
\text { (circularity } \\
\text { values } \times \text { PGFA) }\end{array}$ & 0.031 & Not significant \\
\hline $\begin{array}{l}\text { Filling } \\
\text { quality } \times \text { sealability } \\
\text { (PGFA } \times \text { leakage } \\
\text { rates) }\end{array}$ & 0.219 & Not significant \\
\hline $\begin{array}{l}\text { Root canal } \\
\text { configuration } \times \\
\text { sealability } \\
\text { (circularity values } \times \\
\text { leakage rates) }\end{array}$ & 0.184 & Not significant \\
\hline
\end{tabular}

Abbreviation: PGFA, percentage of gutta-percha filled area. aValues close to 1 mean positive correlation.

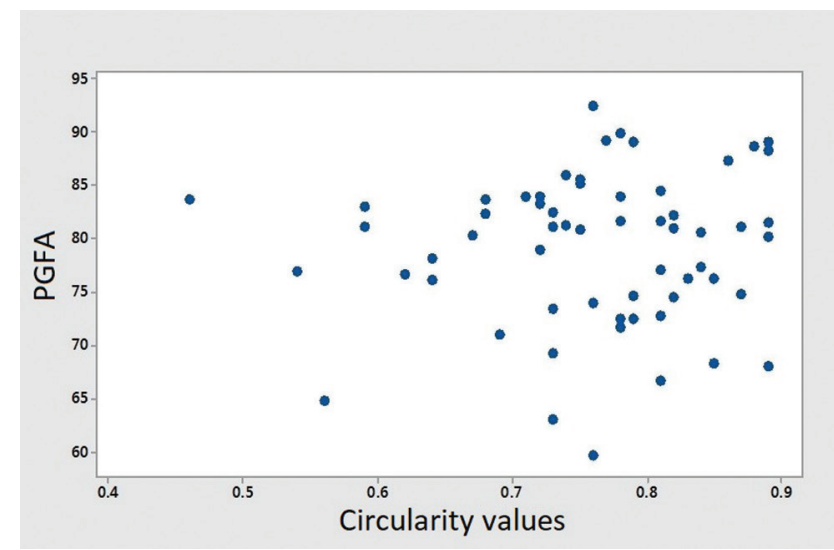

Fig. 2 Correlation between the root canal configuration and filling quality obtained by assessing the circularity and percentage of gutta-percha filled areas values.

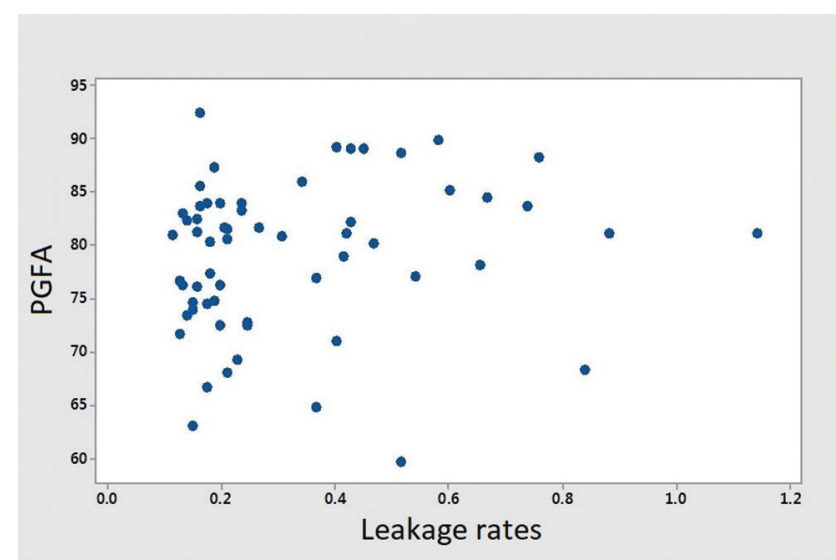

Fig. 3 Correlation between the filling quality and its sealability obtained by assessing the percentage of gutta-percha filled areas and leakage values.

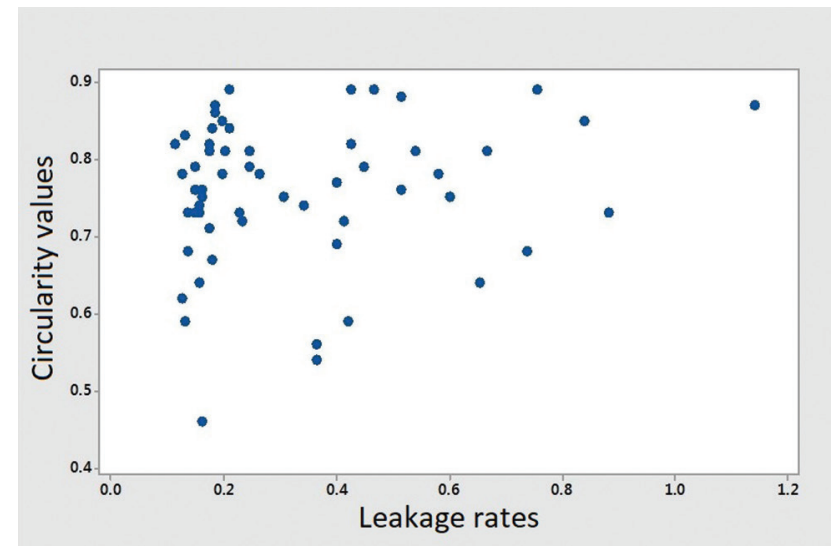

Fig. 4 Correlation between the root canal configuration and filling sealability obtained by assessing the circularity and leakage rate values.

\section{Discussion}

The cleaning, shaping, and filling of flattened root canals represent a challenge to clinicians. ${ }^{16,17}$ Inaccessible areas to the endodontic instruments and chemical substances ${ }^{16}$ are improperly filled by sealer and gutta-percha. ${ }^{17}$ The purpose of the present study was to investigate the correlation between the root canal configuration and the quality of filling. Based on the results obtained, the null hypothesis tested was not rejected, as there was no significant correlation among the three assessed variables (circularity factors, PGFA, and fluid filtration rates).

In order to analyze the possible correlations among the variables of this study, both correct mathematical and statistical approaches were imperative. The circularity factors were established by the application of the following formula: $4 \times$ area of the canal $/ \pi(3.14) \times(\text { largest diameter })^{2} .{ }^{15}$ A single numerical value was established for each tooth by an arithmetical mean of the three values obtained of each root third. The same rationale was used to determine a single value for PGFA. This strategy was established by virtue of a single leakage value existent after performing the fluid filtration test on each specimen to compare the data of all specimens. Furthermore, from a statistical point of view, the use of a single large experimental group is an important experimental design feature because standard correlation analysis posits that any random factor affects only one subject and not others. ${ }^{12}$ This requirement is violated when two or more different experimental groups are created. In fact, there is no rationale to justify the creation of two or three experimental groups when the main objective is restricted to verifying a potential cause-and-effect correlation. ${ }^{12}$ Therefore, since the attempt of this study was to verify a potential cause-andeffect correlation, a single sizeable group was created. ${ }^{12}$

Adequate filling of cleaned and shaped root canals should pack the maximum amount of gutta-percha into the canal and keep the amount of sealer to a minimum because most sealers shrink on setting and dissolve over time, while gutta-percha is highly dimensionally stable. ${ }^{18}$ Therefore, the PGFA was used to evaluate the quality of filling in the present 
investigation, as has previously been performed in several other studies. ${ }^{5,19}$

Different tests have been used to evaluate the sealing ability of endodontic filling materials. ${ }^{6-11}$ However, there is no universally accepted method for assessing leakage. ${ }^{20}$ The variety of methodologies and their assessment parameters are the main reasons for this disagreement. ${ }^{20}$ The lack of standardization and the consequent noncomparability of leakage tests led to $\mathrm{Wu}$ and Wesselink ${ }^{21}$ questioning their relevance and to recommend the use of a fluid filtration system to enhance the reliability of this type of research. In the present study, the established fluid filtration model, as proposed and described by Wu et $\mathrm{al}^{22}$ was used. This method has been shown to be more sensitive than dye penetration. ${ }^{23}$

According to our results, the root canal configuration had no influence on the quality of the filling, as shown by the absence of correlation between the circularity and PGFA values (Spearman's rho $=0.031$ ). Studies have demonstrated the limitations of the lateral compaction technique in filling oval-shaped root canals. ${ }^{24,25}$ Conversely, Weis et al ${ }^{26}$ and Schafer et $\mathrm{al}^{27}$ reported no difference among the lateral compaction technique and others. The controversial results may be primarily credited to the anatomical complexity and distinct methodological designs (systems, instrumentation techniques, etc.). Leoni et $\mathrm{al}^{28}$ assessed the morphological characteristics of 100 mandibular central and lateral incisors using microcomputed tomographic imaging. At 3 and $5 \mathrm{~mm}$ from the root apex, mandibular central incisors showed areas and roundness values of $0.16 \pm 0.12$ and $0.43 \pm 0.22,0.24 \pm 0.20$, and $0.39 \pm 0.18$, respectively. The study did not show values higher than $5 \mathrm{~mm}$ from the apex. In the present study, the root canal preparation was performed up to a 35/0.04 instrument at the WL (-1 mm from the apical foramen). Then, at $-3,-6$, and $-8 \mathrm{~mm}$ from this root portion, the canals were prepared up to approximately $0.43,0.55$, and $0.60 \mathrm{~mm}^{2}$, respectively. This shaping process was responsible for the regularization of the root canal walls in terms of circularity, thereby increasing the filling quality. ${ }^{13,29}$

To enable leakage to be identified by fluid filtration method, there must be at least one continuous empty space between the apical and cervical root thirds. ${ }^{30}$ It means that to register fluid penetration or leakage values, the filling must have at least a continuous vacuum with an open extremity at the cervical portion and another at the apical portion. ${ }^{30}$ Theoretically, the diameter of a continuous empty space may be estimated by using the Poiseuille formula: $\mathrm{V}=\pi \mathrm{P} \mathrm{r}^{4} / 8 \mathrm{~L} \eta$, where $\mathrm{P}$ is the pressure, $\mathrm{r}$ is the radius of a continuous empty space (to be calculated), $\mathrm{L}$ is the length of the empty space, and $\eta$ is the viscosity of the aqueous solution at ambient temperature. ${ }^{12,31}$ In the present study, all the specimens showed variable leakage rates; nevertheless, the quality of the filling determined by the PGFA was satisfactory. The controversial data probably occurred because of the methodology used. ${ }^{30,32}$ Cross-sections from root canal thirds are not able to show continuous empty spaces in which the fluid might potentially run. ${ }^{30,32}$ For this reason, it was not possible to identify significant correlation between the quality of filling and their sealability (Spearman's rho $=0.219$ ).

The root canal configuration also had no influence on the filling sealability by virtue of the absence of correlation between the circularity and fluid filtration rate values (Spearman's rho $=0.184$ ). This result was probably also due to performing adequate fillings, therefore increasing their sealability.

In addition to the factors pointed out above, it must be emphasized that the sealer used in this study-AH Plus-is recognized for its excellent physicochemical properties. ${ }^{33-35}$ It is suggested by the authors that the flow ability and the dimensional stability of this sealer positively affected the filling sealability. ${ }^{33-36}$

\section{Conclusion}

Within the limitations of this in vitro study, it could be stated that the root canal configuration did not affect the quality of the filling and its sealability.

\section{Funding \\ None. \\ Conflict of Interest \\ None declared.}

\section{References}

1 Tomson PL, Simon SR. Contemporary cleaning and shaping of the root canal system. Prim Dent J 2016;5(2):46-53

2 Mello FW, Miguel AFP, Ribeiro DM, et al. The influence of apical extent of root canal obturation on endodontic therapy outcome: a systematic review. Clin Oral Investig 2019;23(5):2005-2019

3 Schilder H. Filling root canals in three dimensions. Dent Clin North Am 1967:723-744

4 Epley SR, Fleischman J, Hartwell G, Cicalese C. Completeness of root canal obturations: Epiphany techniques versus gutta-percha techniques. J Endod 2006;32(6):541-544

5 Libonati A, Montemurro E, Nardi R, Campanella V. Percentage of gutta-percha-filled areas in canals obturated by 3 different techniques with and without the use of endodontic sealer. J Endod 2018;44(3):506-509

6 Reddy A, Garg G, Janardhanan S, Uthappa R, Arora S, Singh NK. An in vitro evaluation of apical leakage in gutta-percha/AH Plus and Resilon/Epiphany-filled root canals using two dye penetration techniques. J Contemp Dent Pract 2019;20(2):152-157

7 Haïkel Y, Freymann M, Fanti V, Claisse A, Poumier F, Watson M. Apical microleakage of radiolabeled lysozyme over time in three techniques of root canal obturation. J Endod 2000;26(3):148-152

8 Alves AMH, Pozzobon MH, Bortoluzzi EA, et al. Bacterial penetration into filled root canals exposed to different pressures and to the oral environment-in vivo analysis. Clin Oral Investig 2018;22(3):1157-1165

9 Sudan PS, Samson EP, Kukreja MK, Khan M, Misurya R, Ismail PMS. A comparative evaluation of apical leakage using three root canal sealants: an in vitro study. J Contemp Dent Pract 2018;19(8):955-958

10 Kuştarci A, Arslan D, Kaya B. Effects of three different irrigating solutions and KTP laser irradiation on apical leakage: an electrochemical study. Acta Odontol Scand 2012;70(5):377-383

11 Moradi S, Disfani R, Baziar H, Daneshvar F, Jafarzadeh H. Use of fluid filtration method to evaluate the effect of master cone 
size on the apical seal of severely curved root canals. J Oral Sci 2013;55(2):93-98

12 Machado R, Back ED, Tomazinho LF. Silva EJNL, Silva Neto UX, Souza EM, Vansan LP. Lack of correlation between radiographic density of filling and fluid infiltration. Dent Press Endod 2014;4(3):42-46

13 van der Sluis LW, Wu MK, Wesselink PR. An evaluation of the quality of root fillings in mandibular incisors and maxillary and mandibular canines using different methodologies. J Dent 2005;33(8):683-688

14 Özkurt-Kayahan Z, Barut G, Ulusoy Z, et al. Influence of post space preparation on the apical leakage of calamus, single-cone and cold lateral condensation obturation techniques: a computerized fluid filtration study. J Prosthodont 2019;28(5):587-591

15 Loizides AL, Kakavetsos VD, Tzanetakis GN, Kontakiotis EG, Eliades G. A comparative study of the effects of two nickel-titanium preparation techniques on root canal geometry assessed by microcomputed tomography. J Endod 2007;33(12):1455-1459

16 Siqueira JF Jr, Pérez AR, Marceliano-Alves MF, et al. What happens to unprepared root canal walls: a correlative analysis using micro-computed tomography and histology/scanning electron microscopy. Int Endod J 2018;51(5):501-508

17 Celikten B, Uzuntas CF, Orhan AI, et al. Evaluation of root canal sealer filling quality using a single-cone technique in oval shaped canals: an in vitro micro-CT study. Scanning 2016;38(2):133-140

18 Whitworth J. Methods of filling root canals: principles and practices. Endod Topics 2005;12:2-24

19 Schäfer E, Schrenker C, Zupanc J, Bürklein S. Percentage of gutta-percha filled areas in canals obturated with cross-linked gutta-percha core-carrier systems, single-cone and lateral compaction technique. J Endod 2016;42(2):294-298

20 Jafari F, Rahimi S, Shahi S, Jafari S. Endodontic microleakage studies: correlation among different methods, clinical relevance, and potential laboratory errors. Minerva Stomatol 2017;66(4):169-177

21 Wu MK, Wesselink PR. Endodontic leakage studies reconsidered. Part I. Methodology, application and relevance. Int Endod J 1993;26(1):37-43

22 Wu MK, De Gee AJ, Wesselink PR, Moorer WR. Fluid transport and bacterial penetration along root canal fillings. Int Endod J 1993;26(4):203-208

23 da Silva Neto UX, de Moraes IG, Westphalen VP, Menezes R, Carneiro E, Fariniuk LF. Leakage of 4 resin-based root-canal sealers used with a single-cone technique. Oral Surg Oral Med Oral Pathol Oral Radiol Endod 2007;104(2):e53-e57

24 Li GH, Niu LN, Selem LC, et al. Quality of obturation achieved by an endodontic core-carrier system with crosslinked gutta-percha carrier in single-rooted canals. J Dent 2014;42(9):1124-1134

25 Keleş A, Alcin H, Kamalak A, Versiani MA. Micro-CT evaluation of root filling quality in oval-shaped canals. Int Endod J 2014;47(12):1177-1184

26 Weis MV, Parashos P, Messer HH. Effect of obturation technique on sealer cement thickness and dentinal tubule penetration. Int Endod J 2004;37(10):653-663

27 Schäfer E, Köster M, Bürklein S. Percentage of gutta-percha-filled areas in canals instrumented with nickel-titanium systems and obturated with matching single cones. J Endod 2013;39(7):924-928

28 Leoni GB, Versiani MA, Pécora JD, Damião de Sousa-Neto M. Micro-computed tomographic analysis of the root canal morphology of mandibular incisors. J Endod 2014;40(5):710-716

29 Keçeci AD, Unal GC, Sen BH. Comparison of cold lateral compaction and continuous wave of obturation techniques following manual or rotary instrumentation. Int Endod J 2005;38(6):381-388

30 Asawaworarit W, Yachor P, Kijsamanmith K, Vongsavan N. Comparison of the apical sealing ability of calcium silicate-based sealer and resin-based sealer using the fluid-filtration technique. Med Princ Pract 2016;25(6):561-565

31 Huybrechts B, Bud M, Bergmans L, Lambrechts P, Jacobs R. Void detection in root fillings using intraoral analogue, intraoral digital and cone beam CT images. Int Endod J 2009;42(8):675-685

32 Raina R, Loushine RJ, Weller RN, Tay FR, Pashley DH. Evaluation of the quality of the apical seal in Resilon/Epiphany and Gutta-Percha/AH Plus-filled root canals by using a fluid filtration approach. J Endod 2007;33(8):944-947

33 Viapiana R, Flumignan DL, Guerreiro-Tanomaru JM, Camilleri J, Tanomaru-Filho M. Physicochemical and mechanical properties of zirconium oxide and niobium oxide modified Portland cement-based experimental endodontic sealers. Int Endod J 2014;47(5):437-448

34 Zhou HM, Shen Y, Zheng W, Li L, Zheng YF, Haapasalo M. Physical properties of 5 root canal sealers. J Endod 2013;39(10):1281-1286

35 Cañadas PS, Berástegui E, Gaton-Hernández P, Silva LA, Leite GA, Silva RS. Physicochemical properties and interfacial adaptation of root canal sealers. Braz Dent J 2014;25(5):435-441

36 Hirai VHG, Machado R, Budziak MCL, Piasecki L, Kowalczuck A, Neto UXDS. Percentage of Gutta-Percha-, sealer-, and voidfilled areas in oval-shaped root canals obturated with different filling techniques: a confocal laser scanning microscopy study. Eur J Dent 2020;14(1):8-12 